\title{
¿Early Detection of Convective Echoes and Their Development Using a Ka-Band Radar Network
}

\author{
Syo Yoshida, ${ }^{\mathrm{a}}$ Ryohei Misumi, ${ }^{\mathrm{b}}$ ANd TAKeshi MAesakA ${ }^{\mathrm{b}}$ \\ ${ }^{a}$ Graduate School of Life and Environmental Sciences, University of Tsukuba, Tsukuba, Japan \\ ${ }^{\mathrm{b}}$ National Research Institute for Earth Science and Disaster Resilience, Tsukuba, Japan
}

(Manuscript received 23 November 2019, in final form 18 September 2020)

\begin{abstract}
Cumulonimbus clouds, which cause local heavy rainfall and urban floods, can develop within 20 min after being detected by operational centimeter-wavelength (X-, C-, or S-band) weather radars. To detect such clouds with greater lead times, Ka-band radars at a wavelength of $8.6 \mathrm{~mm}$ together with operational X-band radars were used in this study. The vertically averaged radar reflectivity (VAR) of convective echoes detected by the Ka-band and X-band radars were defined as mesoscale cloud echoes (MCEs) and mesoscale precipitation echoes (MPEs), respectively. The time series of each echo was analyzed by an echo tracking algorithm. On average, MCEs that developed into MPEs (denoted as developed MCEs) were detected 17 min earlier than the MPEs and 33 min earlier than the peak time of the area-averaged VAR (VARa) for MPEs. Some MCEs dissipated without developing into MPEs (denoted as non-developed MCEs). There were statistically significant differences between the developed and non-developed MCEs in terms of the maximum VARa values, maximum MCEs areas, and increase amounts of the VARa values and MCE areas for the first 6-12 min after their detection. Among these indicators, the maximum VARa for the first 9 min showed the most significant differences. Therefore, an algorithm for predicting MCE development using this indicator is discussed.
\end{abstract}

KEYWORDS: Convective clouds; Rainfall; Radars/Radar observations; Nowcasting

\section{Introduction}

In summer, meso- $\gamma$-scale (spatial scale $2-20 \mathrm{~km}$ ) cumulonimbus clouds can cause localized heavy rainfall. If such a heavy rainfall event occurs in an urban area, even over a short time, it can result in flooding. Because cumulonimbus clouds develop very quickly, heavy rainfall sometimes occurs only $20 \mathrm{~min}$ after such clouds are detected by conventional (S-, C-, or X-band) weather radars (Ishihara 2012; Kim et al. 2012). For flood warning systems, it is therefore important to detect cumulonimbus clouds as early as possible.

Recently, operational X-band radars have been used in Japan to observe cumulonimbus clouds in urban areas. The Japanese Ministry of Land, Infrastructure, Transport, and Tourism installed an extended radar information network (XRAIN) consisting of 39 X-band (wavelength of about $3 \mathrm{~cm}$ ) multiparameter (MP-X) radars. XRAIN can obtain the distribution of rainfall intensity at the surface every minute in major urban areas and can perform a volumetric scan every 5 min. Nowcasts (short-term precipitation forecasts using XRAIN) based on the vertically integrated liquid (VIL) water content (Hirano and Maki 2010, 2018), vertical vorticity estimated from Doppler velocity (Nakakita et al. 2013), and tracking algorithms for precipitation systems (Yoshida et al. 2012) have been proposed. In recent years, X-band phased array weather radars (PAWRs), which can obtain a threedimensional observation within $30 \mathrm{~s}$, have been developed (Yoshikawa et al. 2013; Yoshida et al. 2013; Ushio et al. 2015).

¿ Denotes content that is immediately available upon publication as open access.

Corresponding author: Syo Yoshida, s.yoshida@meci.jp
More recently, a polarimetric PAWR has been developed (Takahashi et al. 2019). The fast observation by PAWRs makes it possible to capture the detailed vertical structure of rapidly developing cumulonimbus clouds. A nowcasting method based on PAWRs that includes vertical advection has also been proposed (Otsuka et al. 2016).

The main target of X-band radars such as MP-X and PAWR is precipitation particles. The $\mathrm{X}$-band radar wavelength cannot be used to observe cloud droplets. To detect cumulonimbus clouds earlier, it is necessary to use millimeter-wave radars. The U.S. Department of Energy has acquired scanning Ka-band (wavelength of $8.5 \mathrm{~mm}$ ) radars in the Atmospheric Radiation Measurement (ARM) Program (Kollias et al. 2014). Borque et al. (2014) showed the advantages of the ARM Kaband radar for observing clouds without precipitation. The Korean Meteorological Administration also operates a scanning Ka-band radar in combination with microwave radiometers to study cloud water content estimation (Oh et al. 2018). A scanning Ka-band radar has also been developed in Japan (Hamazu et al. 2003) to observe fog (Uematsu et al. 2005) and the development of cumulonimbus clouds (Sakurai et al. 2012; Nishiwaki et al. 2013; Misumi et al. 2018). Sakurai et al. (2012) showed that the Ka-band radar can detect the first echoes about 15-25 min earlier than X-band radars, and that a rapid increase of radar reflectivity could be an indicator of cumulonimbus development. Nakakita et al. (2017) showed that a Kaband radar can predict the possibility of local heavy rainfall more than 10 min earlier than X-band radars. Few studies have been conducted on short-term precipitation forecasts using millimeter-wave radars because these radars are easily affected by attenuation and it is difficult to apply them to scan the wide areas necessary for tracking the movement of echoes. Another important reason is that an operational network has not yet been deployed. 


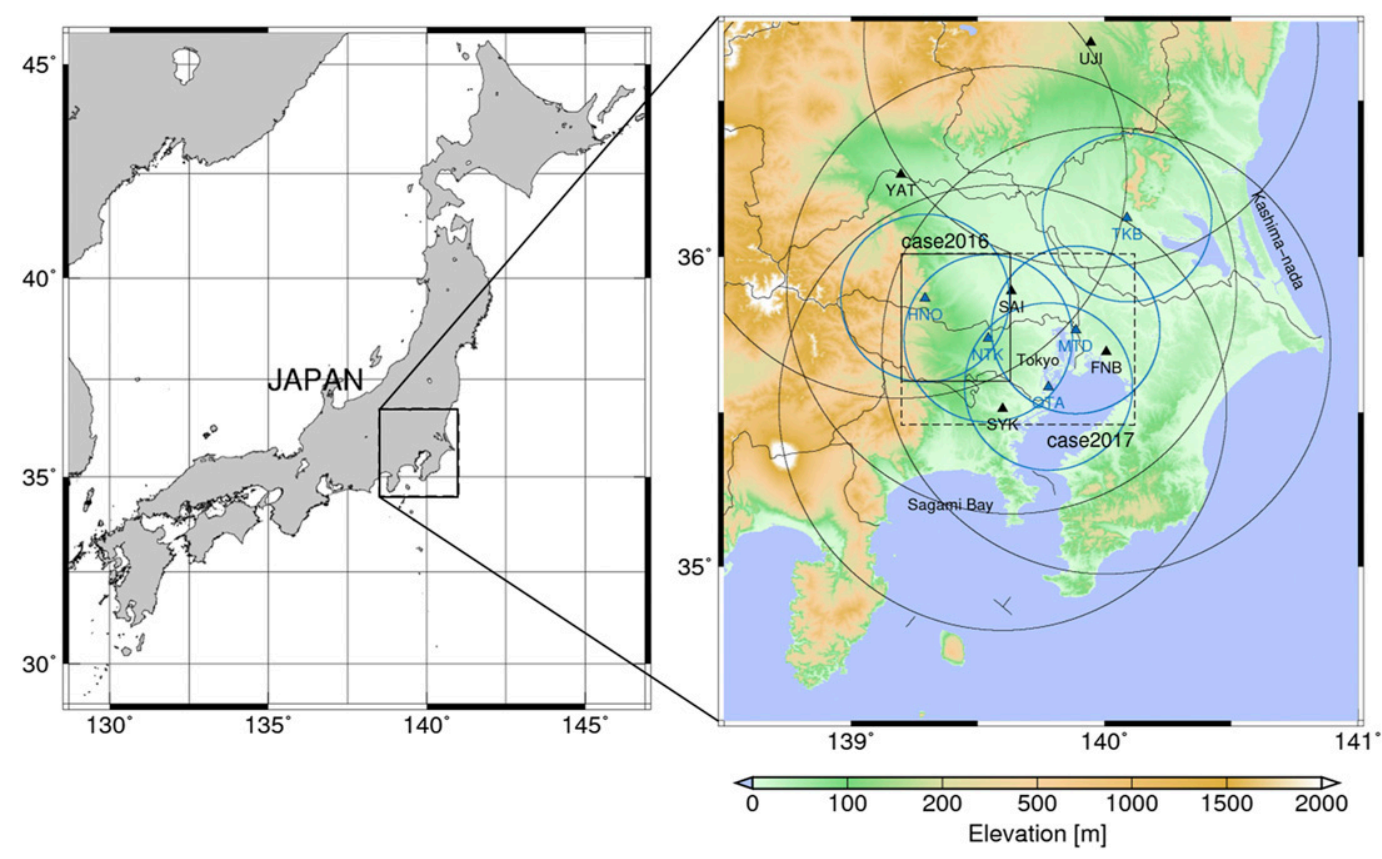

FIG. 1. Locations of radar sites and study areas. Blue triangles and circles represent Ka-band radar sites and observation ranges, respectively. Black triangles and circles represent $\mathrm{X}$-band radar sites and observation ranges, respectively. Black solid and dashed frames in the right figure are the study areas in 2016 and 2017, respectively.

Recently, the National Research Institute for Earth Science and Disaster Resilience has deployed five Ka-band radars in the Tokyo metropolitan area (Maesaka et al. 2015; Maesaka 2018). This radar network enables the tracking of convective echoes from the initial to the mature stages with a plan position indicator (PPI). The radar network reduces the influence of rain attenuation by observing one cumulonimbus cloud with multiple radars. The Ka-band radar network overlaps the XRAIN observation range, and thus different-wavelength radars can observe the formation and development of cumulonimbus clouds simultaneously.

Another problem in short-term precipitation forecasting using millimeter-wave radars is that it is not known whether the detected early radar echoes will develop into heavy precipitation echoes. The early stage echoes detected by millimeterwave radars may dissipate without causing any precipitation on the ground. Therefore, an indicator is necessary to predict whether the detected radar echoes will develop.

In this study, we observed convective echoes using the Kaband radar network and propose an indicator for predicting the development of early echoes. XRAIN was used for tracking convective echoes in the developing and mature stages. The case studies consisted of local heavy rainfall events in the Tokyo metropolitan area in 2016 and 2017. The algorithm for the identification and tracking of convective cells (AITCC, Shimizu and Uyeda 2012) was used to obtain the statistical characteristics of individual convective echoes. Based on the results, a practical indicator for predicting the development of convective echoes is discussed.

\section{Data and methodology}

\section{a. Radars}

In this study, five Ka-band radars located at Tsukuba (TKB), Ota (OTA), Hanno (HNO), Nishitokyo (NTK), and Matsudo (MTD) were used. These radars were installed to cover densely populated areas in the Tokyo metropolitan area (Fig. 1). The analysis domains correspond to the observation areas of HNO

TABLE 1. Specifications of Ka-band radars.

\begin{tabular}{|c|c|c|c|c|c|}
\hline & TKB & OTA & $\mathrm{HNO}$ & NTK & MTD \\
\hline Frequency & $34.84 \mathrm{GHz}$ & $34.86 \mathrm{GHz}$ & $34.88 \mathrm{GHz}$ & $34.91 \mathrm{GHz}$ & $34.93 \mathrm{GHz}$ \\
\hline Beamwidth & & & $0.31^{\circ}$ & & \\
\hline Pulse width & & & $1.0 \mu \mathrm{s}$ (short) $/ 55 \mu \mathrm{s}$ (long) & & \\
\hline PRF & & & Dual, $1980 \mathrm{~Hz} / 1584 \mathrm{~Hz}$ & & \\
\hline \multirow[t]{2}{*}{ Noise level } & $-110 \mathrm{dBm}$ (short) & $-113 \mathrm{dBm}$ (short) & $-112 \mathrm{dBm}$ (short) & $-114 \mathrm{dBm}$ (short) & $-110 \mathrm{dBm}$ (short) \\
\hline & $-126 \mathrm{dBm}$ (long) & $-125 \mathrm{dBm}$ (long) & $-126 \mathrm{dBm}$ (long) & $-128 \mathrm{dBm}$ (long) & $-123 \mathrm{dBm}$ (long) \\
\hline Range interval & & & $150 \mathrm{~m}$ & & \\
\hline Products & & $Z, V, W, Z_{\mathrm{DR}}, K_{\mathrm{dp}}, \rho_{\mathrm{hv}}$ & & & \\
\hline
\end{tabular}



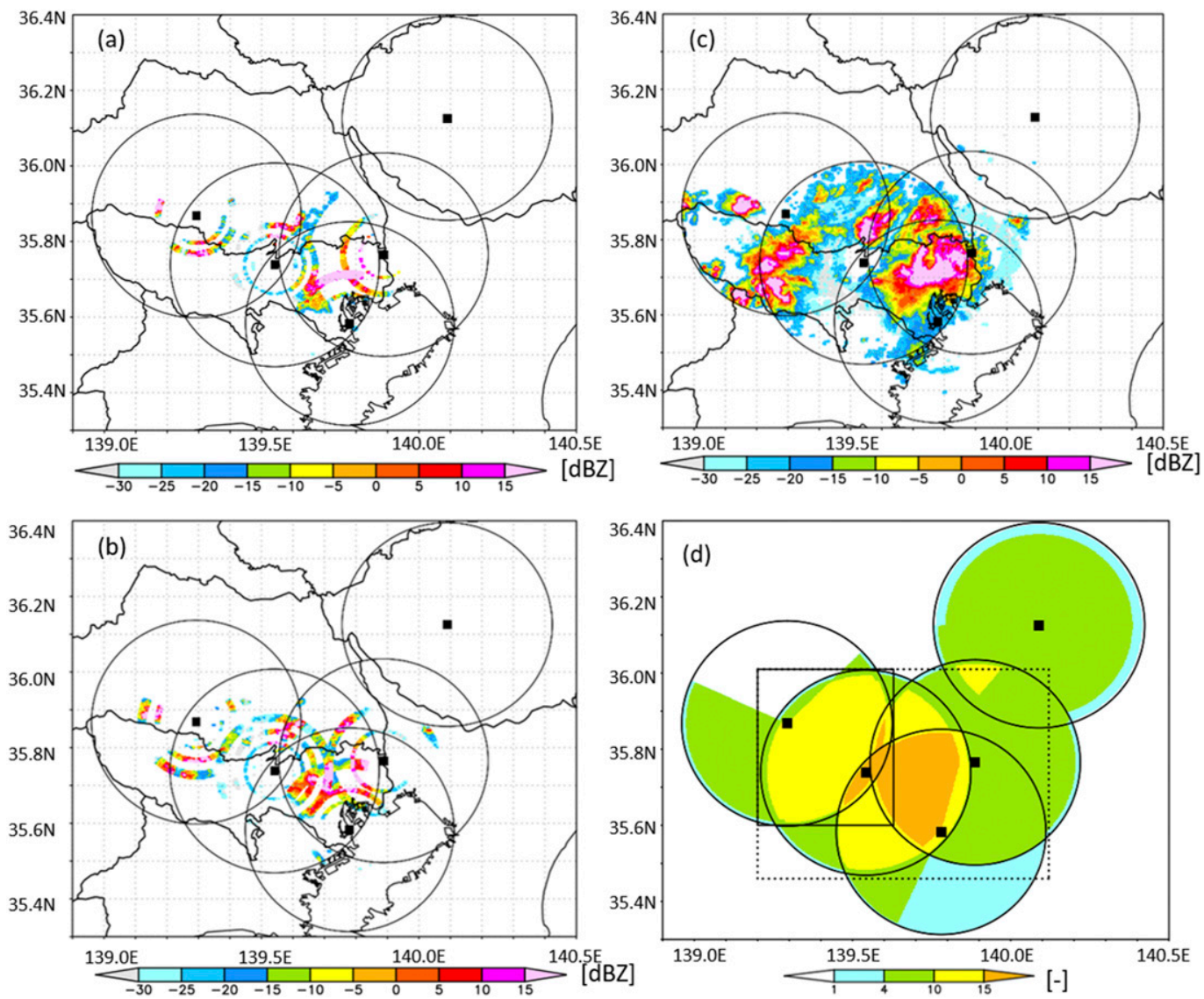

FIG. 2. Reflectivity of Ka-band radars at altitudes of (a) 3000 and (b) $4000 \mathrm{~m}$. (c) VAR and (d) the number of PPIs that contribute to VAR. Circles indicate the observation range of Ka-band radars, whose locations are denoted by black squares. Black solid and dashed frames in (d) are the study areas in 2016 and 2017, respectively (see Fig. 1).

and NTK in 2016 and those of all five radars in 2017 (solid and dashed frames in Fig. 1).

The Ka-band radars use frequencies between 34.8 and $34.9 \mathrm{GHz}$ and have a beamwidth of $0.31^{\circ}$. A pulse width of $55 \mu$ s (long pulse) is usually used with pulse compression technology to improve range resolution and sensitivity. However, such long pulses cannot be used to observe radar echoes within $8.7 \mathrm{~km}$ of a radar; this range is covered by short pulses $(1.0 \mu \mathrm{s})$. The maximum observation range is $30 \mathrm{~km}$ and the range resolution is $150 \mathrm{~m}$. The minimum detectable reflectivity is about $-17 \mathrm{dBZ}$ in dual-polarization mode (TKB, OTA, and HNO) and about $-20 \mathrm{dBZ}$ in singlepolarization mode (NTK and MTD) at the $20-\mathrm{km}$ distance. Each radar performs PPI observations at 4-6 elevation angles every $3 \mathrm{~min}$ (TKB: $5.2^{\circ}, 8.0^{\circ}, 11.5^{\circ}, 15.7^{\circ}, 20.8^{\circ}, 27.2^{\circ}$; OTA: $1.6^{\circ}, 4.5^{\circ}, 7.5^{\circ}, 10.6^{\circ}, 15.0^{\circ}$; HNO: $5.0^{\circ}, 7.0^{\circ}, 10.5^{\circ}, 14.9^{\circ}$, $20.3^{\circ}$; NTK: $6.8^{\circ}, 10.3^{\circ}, 14.4^{\circ}, 19.5^{\circ}, 26.21^{\circ}$; MTD: $2.7^{\circ}, 5.8^{\circ}$, $\left.10.0^{\circ}, 16.4^{\circ}\right)$. The outputs are the radar reflectivity $Z$, Doppler velocity $V$, and spectrum width $W$ for NTK and MTD, and the differential reflectivity $Z_{\mathrm{DR}}$, specific differential

TABLE 2. Specifications of X-band radars.

\begin{tabular}{|c|c|c|c|c|c|}
\hline & SAI & SYK & FNB & YAT & UJI \\
\hline Frequency & $9.76 \mathrm{GHz}$ & $9.78 \mathrm{GHz}$ & $9.72 \mathrm{GHz}$ & $9.74 \mathrm{GHz}$ & $9.78 \mathrm{GHz}$ \\
\hline Beamwidth & $\begin{array}{l}1.04^{\circ}(\mathrm{H}) \\
1.06^{\circ}(\mathrm{V})\end{array}$ & $1.05^{\circ}(\mathrm{H}, \mathrm{V})$ & $\begin{array}{l}1.07^{\circ}(\mathrm{H}) \\
1.04^{\circ}(\mathrm{V})\end{array}$ & $1.03^{\circ}(\mathrm{H}, \mathrm{V})$ & $1.03^{\circ}(\mathrm{H}, \mathrm{V})$ \\
\hline Pulse width & $\begin{array}{l}1.0 \mu \mathrm{s} \text { (short) } \\
48.0 \mu \mathrm{s} \text { (long) }\end{array}$ & $1.0 \mu \mathrm{s}$ & $\begin{array}{l}1.0 \mu \mathrm{s} \text { (short) } \\
32.0 \mu \mathrm{s} \text { (long) }\end{array}$ & $\begin{array}{l}1.0 \mu \mathrm{s} \text { (short) } \\
32.0 \mu \mathrm{s} \text { (long) }\end{array}$ & $\begin{array}{l}1.0 \mu \mathrm{s} \text { (short) } \\
32.0 \mu \mathrm{s} \text { (long) }\end{array}$ \\
\hline PRF & & SYK: dual, 18 & Iz/1440 Hz; the other & al, $1980 \mathrm{~Hz} / 1584 \mathrm{~Hz}$ & \\
\hline Noise level & $\begin{array}{l}-113 \mathrm{dBm} \text { (short) } \\
-107 \mathrm{dBm} \text { (long) }\end{array}$ & $-107 \mathrm{dBm}$ & $\begin{array}{l}-102 \mathrm{dBm} \text { (short) } \\
-116 \mathrm{dBm} \text { (long) }\end{array}$ & $\begin{array}{l}-102 \mathrm{dBm} \text { (short) } \\
-117 \mathrm{dBm} \text { (long) }\end{array}$ & $\begin{array}{l}-102 \mathrm{dBm} \text { (short) } \\
-117 \mathrm{dBm} \text { (long) }\end{array}$ \\
\hline $\begin{array}{l}\text { Range interval } \\
\text { Products }\end{array}$ & & & $\begin{array}{c}150 \mathrm{~m} \\
Z, V, W, Z_{\mathrm{DR}}, K_{\mathrm{d}_{\mathrm{r}}}\end{array}$ & & \\
\hline
\end{tabular}




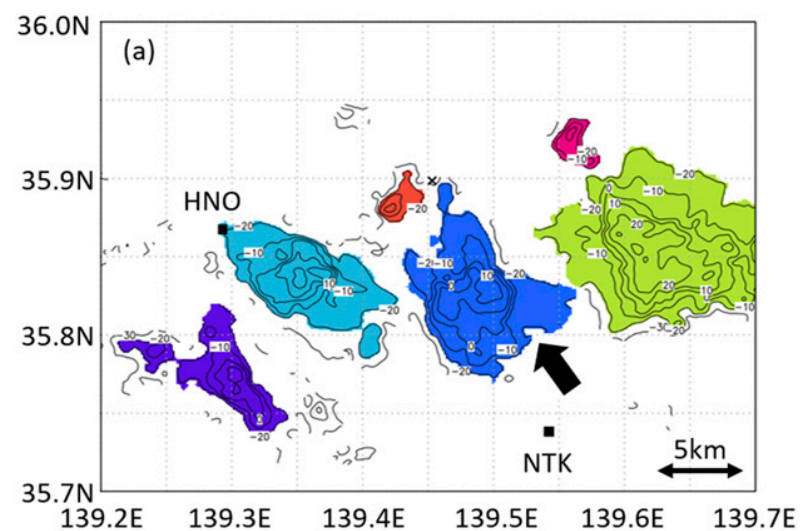

(b)

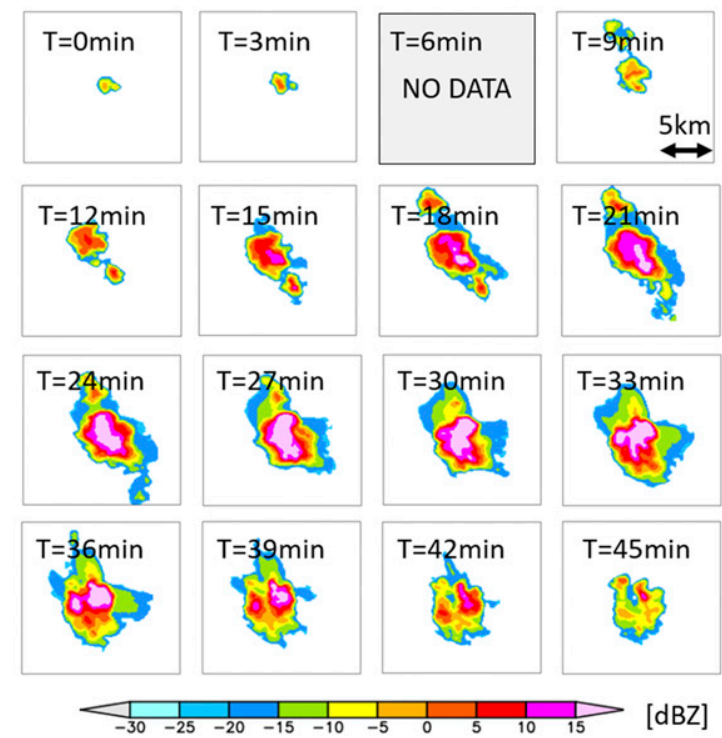

FIG. 3. (a) Examples of MCE detection and tracking. Colored areas correspond to detected MCEs. Contour lines for VAR are drawn every $10 \mathrm{dBZ}$. Black squares indicate the HNO and NTK sites. (b) Time series of VAR for MCE indicated by black arrow in (a).

phase shift $K_{\mathrm{dp}}$, and correlation coefficient $\rho_{\mathrm{hv}}$, as well as $Z, V$, and $W$, for the other radars. The specifications of the Ka-band radars are listed in Table 1.

In general, Ka-band radars are strongly affected by attenuation because of their short wavelengths compared to those of conventional weather radars. Here, attenuation correction for the atmosphere was performed by assuming an attenuation rate of $0.15 \mathrm{~dB} \mathrm{~km}^{-1}$ (one way). Generally, the specific attenuation depends on temperature and humidity, so it is necessary to consider their time and space variations for accurate correction. However, it is difficult to obtain their temporal and spatial distributions within the observation range. Therefore, the correction was made using a constant value.

Attenuation corrections for Ka-band reflectivity for precipitation particles or cloud droplets have been proposed using dual-wavelength radars (Chandrasekar et al. 2003), a vertical
TABLE 3. Cases used for analysis.

\begin{tabular}{cccc}
\hline \hline & & \multicolumn{2}{c}{ No. of MCEs } \\
\cline { 3 - 4 } No. & Time and date & Developed & Non-developed \\
\hline 1 & 1300-1700 JST 4 Aug 2016 & 6 & 1 \\
2 & $1300-1700$ JST 9 Aug 2017 & 2 & 7 \\
3 & $1400-1700$ JST 19 Aug 2017 & 2 & 7 \\
4 & 1000-1400 JST 30 Aug 2017 & 5 & 24 \\
& Total No. of MCEs & 15 & 39 \\
\hline
\end{tabular}

pointing radar (Matrosov 2005), and dual Ka-band radars (Nishikawa et al. 2016). However, the main target of this study is early convective echoes, which appear in environments where the attenuation due to other convective echoes is negligible. Moreover, the networked Ka-band radars reduce the influence of attenuation by observing one echo with multiple radars. Therefore, no correction was made for precipitation particles or cloud droplets.

To remove non-meteorological echoes (such as insects), we regarded cloud echoes when the 5 bins $\times 5$ rays moving average of the received power $\overline{P_{r}}$ was larger than a certain noise level:

$$
\overline{P_{r}}=10 \log \left(\sum_{-2 \leq \text { ray } \leq 2-2 \leq \text { bin } \leq 2} 10^{\frac{P_{r}}{10}}\right) \geq \text { noise level, }
$$

where $P_{r}$ is the received power from the targets. This procedure is adopted because the spatial fluctuations differ between meteorological and non-meteorological echoes. Polarimetric methods (e.g., $\rho_{\mathrm{hv}}$ thresholding) would be more reliable, but two of the five Ka-band radars are non-polarimetric and these methods were not applied in this study. The noise level in Eq. (1) was calculated by adding the dispersion $(4 \mathrm{~dB})$ to the average value of the received power for a clear sky. The noise levels are approximately $\leq-110 \mathrm{dBm}$ for short pulses and $\leq-123 \mathrm{dBm}$ for long pulses, though the values slightly vary with radar. Furthermore, data that included spurious echoes such as range side lobes and second trips were excluded.

The PPI obtained at each radar site was converted to a constant altitude PPI (CAPPI) of $Z$ using the Cressman interpolation method. The horizontal and vertical grid resolutions for the interpolation were 150 and $100 \mathrm{~m}$, respectively, considering the beam spread $(162 \mathrm{~m})$ at $30 \mathrm{~km}$ from the radar. After interpolation, horizontal smoothing with a $3 \times 3$ mesh median filter was applied. For grids that could not be interpolated by available data, a $5 \times 5$ mesh Gaussian filter was applied. Figures $2 \mathrm{a}$ and $2 \mathrm{~b}$ show the CAPPI of $Z$. Because the interval of the elevation angles is large compared to the beamwidth, the interpolation gaps are conspicuous. Therefore, to fill these gaps and utilize the reflectivity at all levels, we calculated the vertically averaged reflectivity (VAR) from the CAPPI data as

$$
\mathrm{VAR}_{i, j}=10 \log \left(\frac{1}{n} \sum_{k} z_{i j k}\right)
$$

where the subscripts $i, j$, and $k$ represent the grid points along the $x, y$, and $z$ axes of the CAPPI data, respectively; $z_{i j k}$ is the 

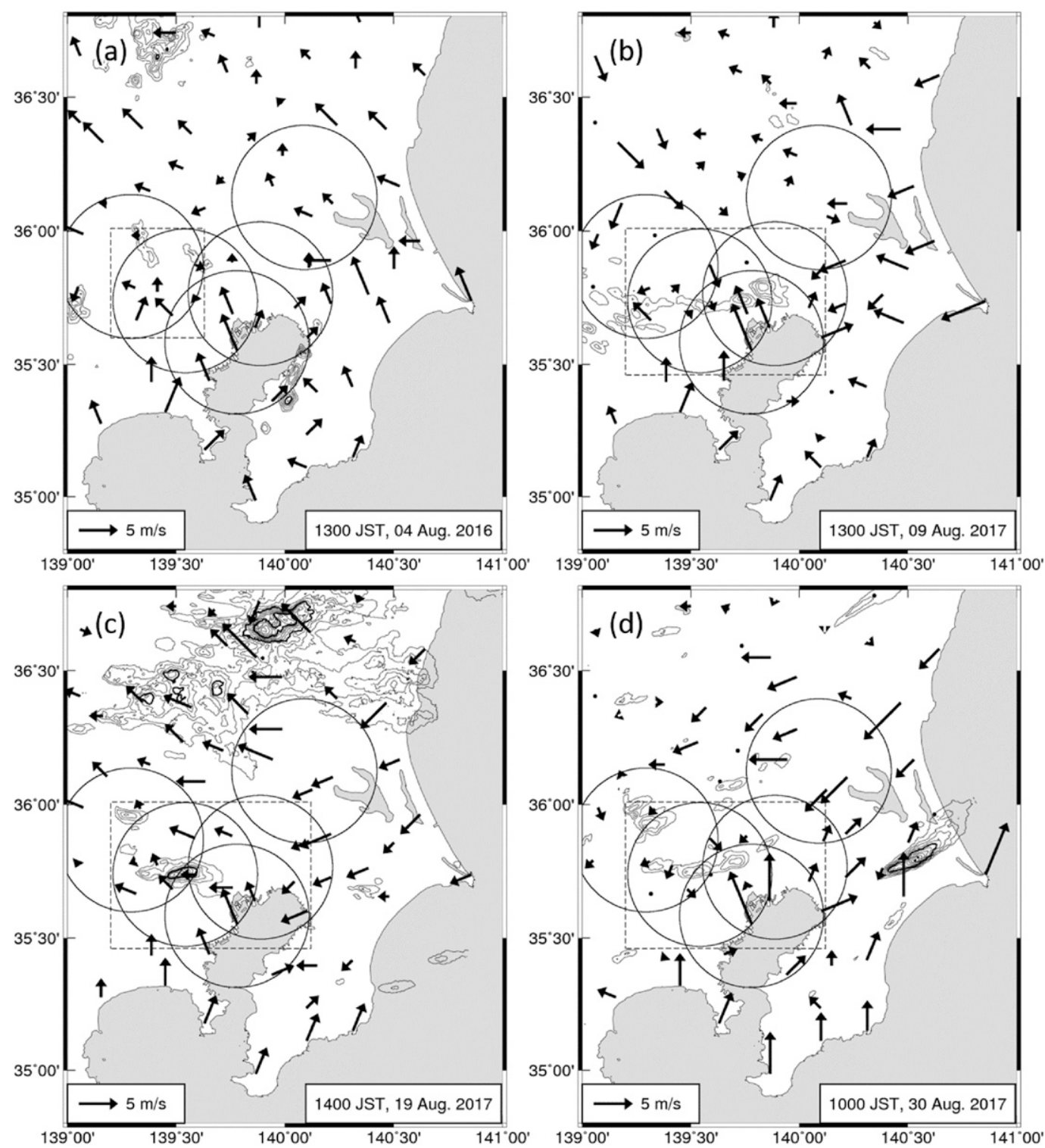

FIG. 4. Surface wind observed at the Automated Meteorological Data Acquisition System (AMeDAS; arrows) and total rainfall amount observed by XRAIN (contours) in the case studies. Winds were observed at (a) 1300 JST 4 Aug 2016, (b) 1300 JST 9 Aug 2017, (c) 1400 JST 19 Aug 2017, and (d) 1000 JST 30 Aug 2017. Contours are drawn every $10 \mathrm{~mm}$, and thick lines indicate $50 \mathrm{~mm}$.

radar reflectivity at $(i, j, k)\left(\mathrm{mm}^{6} \mathrm{~m}^{-3}\right)$; and $n$ is the number of vertical grids where $z_{i j k}>0$ at $(i, j)$. The unit of the VAR is $\mathrm{dBZ}$. By adopting VAR, a continuous horizontal distribution for the reflectivity was obtained (Fig. 2c). However, because VAR projects three-dimensional information onto a horizontal plane, it should be noted that the data at different elevations may be mixed in each horizontal grid. The number of PPIs that contribute to VAR varies depending on the distance from the radar; it is more than 10 in the analysis domains (Fig. 2d). VAR is similar to VIL, which was not used in this study because it is difficult to obtain the cloud water content from the reflectivity of a Ka-band radar, especially when drizzle is present (Khain et al. 2008).
To analyze precipitation echoes, five operational X-band radars, respectively located at Saitama (SAI), Shin-Yokohama (SYK), Funabashi (FNB), Yattajima (YAT), and Ujiie (UJI), were also used. Their minimum detectable reflectivity is about $2 \mathrm{dBZ}$ (SAI), $5 \mathrm{dBZ}$ (SYK), and $10 \mathrm{dBZ}$ (FNB, YAT, and UJI, respectively) at a $30-\mathrm{km}$ distance. The maximum observation range of these radars is $80 \mathrm{~km}$, and their range resolution is $150 \mathrm{~m}$. PPI observations at 12 elevation angles are routinely performed every $5 \mathrm{~min}$, where the two underlined elevation angles below are scanned alternately every minute to estimate the rainfall intensity at the surface (SAI: $1.4^{\circ}, 2.4^{\circ}, 0.8^{\circ}$, $3.6^{\circ}, 4.9^{\circ}, 6.3^{\circ}, 7.9^{\circ}, 9.7^{\circ}, 11.8^{\circ}, 14.2^{\circ}, 16.9^{\circ}, 20.0^{\circ}$; SYK: $1.7^{\circ}$, $2.6^{\circ}, 1.0^{\circ}, 3.8^{\circ}, 5.1^{\circ}, 6.5^{\circ}, 8.1^{\circ}, 9.9^{\circ}, 11.9^{\circ}, 14.2^{\circ}, 16.9^{\circ}, 20.0^{\circ}$; 


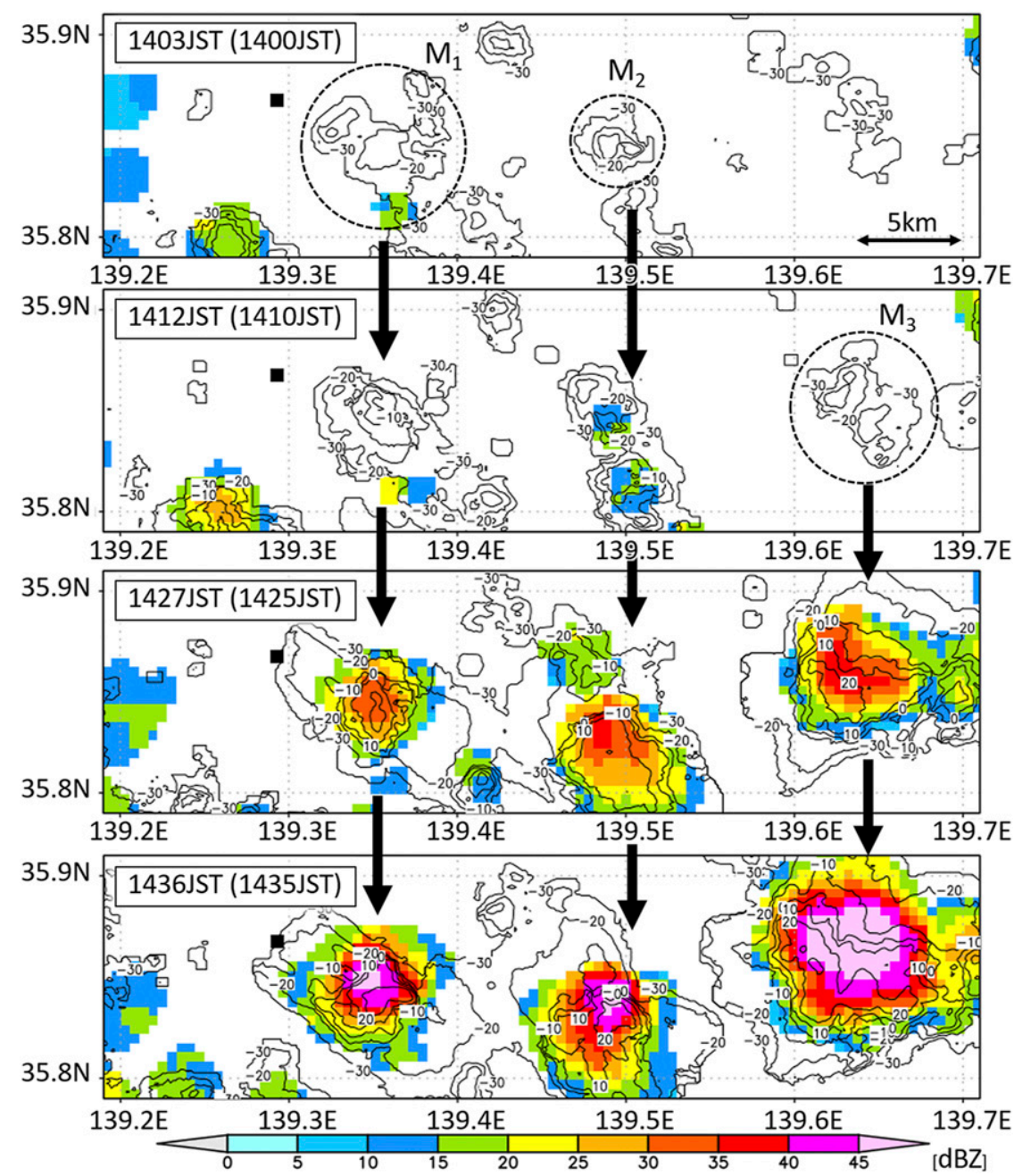

FIG. 5. VAR for developing MCEs and MPEs on 4 Aug 2016. Contours and shaded grid represent VAR for Ka-band and X-band radars, respectively. Time in the figure is for Ka-band radar measurements. Time in parentheses is for X-band radar measurements. The black square indicates the HNO radar site. Broken-line circles represent first MCEs. The average height of CAPPI data contributing to each VAR of Ka-band radars was $2.7 \mathrm{~km}$ at $1403 \mathrm{JST}$ and $3.8 \mathrm{~km}$ at 1436 JST.

FNB: $1.6^{\circ}, 2.6^{\circ}, 0.6^{\circ}, 3.8^{\circ}, 5.1^{\circ}, 6.5^{\circ}, 8.1^{\circ}, 9.9^{\circ}, 11.9^{\circ}, 14.2^{\circ}, 16.9^{\circ}$, $20.0^{\circ}$; YAT: $1.6^{\circ}, 2.7^{\circ}, 0.5^{\circ}, 3.9^{\circ}, 5.2^{\circ}, 6.6^{\circ}, 8.2^{\circ}, 10.0^{\circ}, 12.0^{\circ}, 14.2^{\circ}$, $16.8^{\circ}, 20.0^{\circ}$; $\overline{\mathrm{UJI}}: \overline{1.4^{\circ}}, 3.0^{\circ}, 0.7^{\circ}, 2.2^{\circ}, 4.2^{\circ}, 5.6^{\circ}, 7.2^{\circ}, 9.1^{\circ}, 11.3^{\circ}$, $\left.13.8^{\circ}, 16.7^{\circ}, 20.0^{\circ}\right)$. The products of these radars are $Z, V, W$, $Z_{\mathrm{DR}}, K_{\mathrm{dp}}$, and $\rho_{\mathrm{hv}}$. Table 2 lists the specifications of the X-band radars. Detailed quality control methods of the X-band radars, including attenuation correction, are shown in Maesaka et al. (2011). Similar to Ka-band radars, three-dimensional data (horizontal and vertical grid intervals are 500 and $250 \mathrm{~m}$, respectively) for the reflectivity were created using the Cressman interpolation method to calculate the VAR.

\section{b. Definition of echoes}

For the statistical analysis, radar echoes were classified as follows. In the VAR derived from Ka-band radars, if an area enclosed by a contour line of $-20 \mathrm{~dB} Z$ was between 3 and
$400 \mathrm{~km}^{2}$, these echoes are denoted mesoscale cloud echoes (MCEs). For X-band radars, the threshold for the VAR was set to $5 \mathrm{dBZ}$ and the echoes are denoted mesoscale precipitation echoes (MPEs). These thresholds almost correspond to the minimum detectable reflectivity for both radars. The MCE and MPE areas were automatically calculated by the AITCC by counting the number of grids within the outermost contours. The upper limit of the MCE (MPE) area was defined to exclude echoes larger than the meso- $\gamma$-scale $(2-20 \mathrm{~km})$. However, there were no such large echoes in this study. The lower limit of the area was defined to exclude non-precipitation echoes such as ground clutter, which could not be removed by the moving target indication (MTI) method. The MCEs that developed into MPEs are denoted as developed MCEs and those that did not develop into MPEs are denoted as nondeveloped MCEs in this paper. 

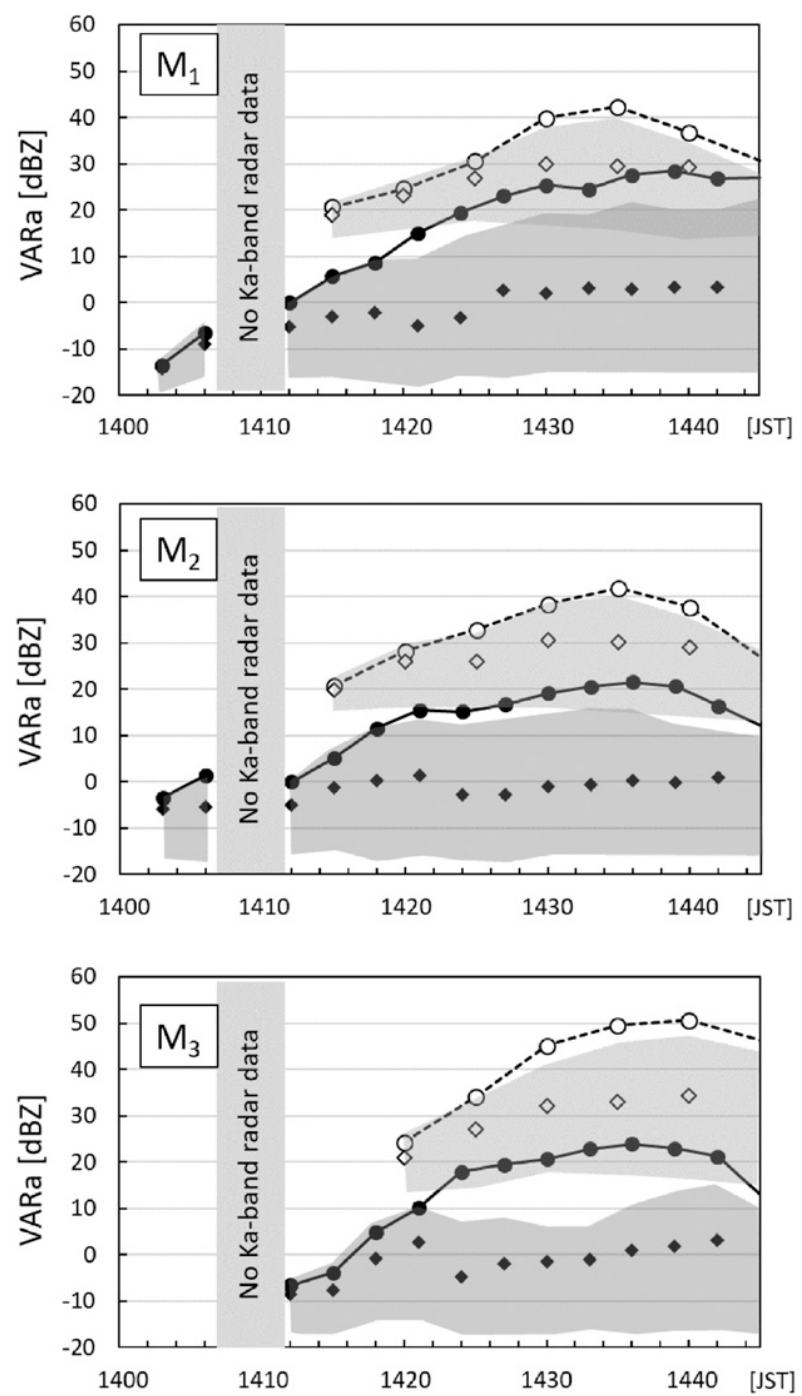

FIG. 6. Time series of VARa of MCEs (black circles) and MPEs (white circles) on 4 Aug 2016. M1, M2, and M3 in the figure are MCEs identified in Fig. 5. Diamonds represent the 50th percentile of VAR within the MCE and MPE regions, and shaded areas represent the 25th and 75th percentiles. M3 may have existed during the outage of the Ka-band radar (1409 JST).

\section{c. Detection and tracking of echoes}

The AITCC was used for the detection and tracking of MCEs and MPEs. This algorithm identifies individual convective cells (CCs) and their groups (convective cell groups, CCGs). First, the AITCC extracts the regions enclosed by contour lines at a certain threshold of reflectivity. The region is defined as a CCG. Then, the CCG is divided into CCs, which consist of a single reflectivity peak and its surrounding areas. In the present study, CCGs derived from the VAR are defined as MCEs or MPEs. They were detected every 3 and 5 min, respectively.

The CCG tracking method in the AITCC is as follows. First, the average movement vectors (MVs) of all CCGs are calculated by the cross-correlation method using radar echoes at successive time steps. Next, MVs for individual CCGs are identified by linking the past and current CCGs using the average MVs. If there are multiple links to one CCG, the similarity is evaluated based on the area, shape, and reflectivity (maximum and average) between the past and current CCGs. If there are multiple CCGs with high similarity, they are determined to be merged/separated. In this study, the tracking results were manually checked; when the characteristics of an MCE (MPE) at a certain time differed significantly from those at the previous time step, they were treated as the formation of a new MCE or MPE. In addition, the MCEs (MPEs) that formed or extended outside of the study area, or that dissipated within two time steps, were excluded from the analysis. Figure 3 shows an example of the MCE detection/tracking results obtained with the AITCC.

\section{d. Cases}

We studied local heavy rainfall events that occurred in the study area in August 2016 and 2017. Nakakita et al. (2016) defined a local heavy rainfall event as rainfall with an intensity of $50 \mathrm{~mm} \mathrm{~h}^{-1}$ observed within $30 \mathrm{~min}$ of its onset. In 2016 and 2017, there were four local heavy rainfall events in the study area (Table 3, Fig. 4). All of the cases were in August because deep convection frequently occurs under weak synoptic-scale forcing in the study area. In these cases, local heavy rainfall occurred after the convergence of sea breezes from the east and south (Fig. 4). Such conditions are frequently observed when local heavy rainfall occurs around Tokyo (Fujibe et al. 2002; Saito et al. 2018). Therefore, the study cases are typical of convective events in the Tokyo metropolitan area.

\section{Results}

\section{a. Characteristics of developed MCEs}

In this section, the characteristics of MCEs are examined based on the time variation of the VAR. Figure 5 shows the horizontal distribution of VAR for developed MCEs observed on 4 August 2016. Two MCEs (M1, M2) were detected at 1403 JST $(\mathrm{UTC}+9 \mathrm{~h})$, and another MCE (M3) formed to the east of M2 at 1412 JST. MPEs for M1 and M2 were detected at 1415 JST, and the MPE for M3 formed at 1420 JST. They continued to develop, reaching their peak VAR at 32 min after their first detection. Figure 6 shows the time series of the area-averaged VAR (VARa) of the MCEs and MPEs. The thresholds for the VAR of MCEs and MPEs are -20 and $5 \mathrm{dBZ}$, respectively, as described above. VAR varied about two orders of magnitude within a MCE (MPE) (unit: $\mathrm{mm}^{-6} \mathrm{~m}^{-3}$ ), and VARa values were close to the 75th percentile of VAR in the early stages of MCEs (MPEs). The time differences $\left(t_{1}\right)$ of the first detection between the MCE and MPE were $12 \mathrm{~min}$ for M1 and M2 and 8 min for $\mathrm{M} 3$, and the time differences $\left(t_{2}\right)$ between the first detection of the MCE and the first VARa peak of the MPE (hereafter referred to as the peak time) were $32 \mathrm{~min}$ for M1 and M2 and $28 \mathrm{~min}$ for M3. At the time when the MCEs formed, their VARa values differed greatly $(-13.5,-3.4$, and $-6.6 \mathrm{dBZ}$ for M1, M2, and M3, respectively). However, 
TABLE 4. Characteristics of developed MCEs. The terms $t_{1}$ and $t_{2}$ indicate the lead time to the first detection of MPE and to the first peak time of MPE, respectively. "Initial" means the initial values of MCEs, and "Max" and " $\Delta$ " mean the maximum values and increase amounts, respectively, in the period between the first detection of MCEs and MPEs.

\begin{tabular}{|c|c|c|c|c|c|c|c|c|c|}
\hline \multirow[b]{2}{*}{ MCE No. } & \multirow[b]{2}{*}{ Case No. } & \multirow[b]{2}{*}{$t_{1}(\min )$} & \multirow[b]{2}{*}{$t_{2}(\min )$} & \multicolumn{3}{|c|}{ VARa } & \multicolumn{3}{|c|}{ MCE area } \\
\hline & & & & Initial (dBZ) & $\operatorname{Max}(\mathrm{dBZ})$ & $\Delta(\mathrm{dB})$ & Initial $\left(\mathrm{km}^{2}\right)$ & $\operatorname{Max}\left(\mathrm{km}^{2}\right)$ & $\Delta\left(\mathrm{km}^{2}\right)$ \\
\hline 1 & 1 & 12 & 32 & -13.5 & 5.7 & 19.2 & 4.6 & 18.2 & 13.5 \\
\hline 2 & 1 & 12 & 32 & -3.4 & 5.2 & 8.6 & 3.6 & 21.0 & 17.4 \\
\hline 3 & 1 & 8 & 28 & -6.6 & 4.8 & 11.4 & 4.8 & 21.6 & 16.8 \\
\hline 4 & 1 & 10 & 25 & -5.9 & 8.5 & 14.4 & 6.2 & 12.7 & 6.5 \\
\hline 5 & 1 & 17 & 17 & -14.8 & 19.7 & 34.5 & 4.0 & 24.7 & 20.6 \\
\hline 6 & 1 & 6 & 16 & -13.6 & 3.1 & 16.7 & 4.6 & 8.4 & 3.7 \\
\hline 7 & 2 & 16 & 36 & -13.4 & 1.1 & 14.5 & 4.7 & 24.6 & 19.9 \\
\hline 8 & 2 & 13 & 43 & -7.4 & 8.7 & 16.1 & 6.1 & 31.3 & 25.2 \\
\hline 9 & 3 & 11 & 41 & -7.7 & 8.8 & 16.5 & 13.5 & 35.5 & 21.9 \\
\hline 10 & 3 & 24 & 29 & -10.4 & 20.6 & 31.0 & 4.5 & 41.2 & 36.7 \\
\hline 11 & 4 & 33 & 53 & -15.9 & 8.0 & 23.9 & 5.5 & 73.4 & 67.9 \\
\hline 12 & 4 & 8 & 28 & -14.1 & 2.5 & 16.6 & 9.5 & 42.4 & 32.9 \\
\hline 13 & 4 & 14 & 24 & -11.7 & 13.7 & 25.4 & 10.5 & 41.5 & 31.0 \\
\hline 14 & 4 & 50 & 65 & -4.6 & 8.5 & 13.1 & 4.6 & 52.6 & 48.0 \\
\hline 15 & 4 & 16 & 21 & -16.0 & 10.7 & 26.7 & 5.9 & 55.4 & 49.5 \\
\hline \multicolumn{2}{|c|}{ Mean value } & 16.7 & 32.7 & -8.6 & 12.9 & 19.2 & 6.2 & 33.6 & 27.4 \\
\hline
\end{tabular}

the areas of initial MCEs were similar $\left(4.6,3.6\right.$, and $4.8 \mathrm{~km}^{2}$, respectively). The areas increased to $20 \mathrm{~km}^{2}$ when the MPEs were detected. In this case, six developed MCEs were detected.

Table 4 shows the characteristics of 15 developed MCEs. The mean values of $t_{1}$ and $t_{2}$ were 16.7 and $32.7 \mathrm{~min}$, respectively. On average, the increase amount of VARa ( $\triangle \mathrm{VARa})$ in the period between the first detection of MCEs and MPEs was $19.2 \mathrm{~dB}$ and the average of the maximum VARa (MaxVARa) during this period was $12.9 \mathrm{~dB} Z$. The average increment of the MCE areas ( $\triangle$ AREA) was $27.4 \mathrm{~km}^{2}$, and the average of the maximum MCE areas (MaxAREA) was $33.6 \mathrm{~km}^{2}$ in this period.

\section{b. Indicator of MCE development}

In this section, we compare the developed MCEs with nondeveloped MCEs to find an indicator to predict MCE development. There were 39 non-developed MCEs. The mean values of the initial VARa and the areas of these MCEs were $-10.4 \mathrm{dBZ}$ and $4.6 \mathrm{~km}^{2}$, respectively, which are comparable to those of the developed MCEs $\left(-8.6 \mathrm{dBZ}\right.$ and $\left.6.2 \mathrm{~km}^{2}\right)$.
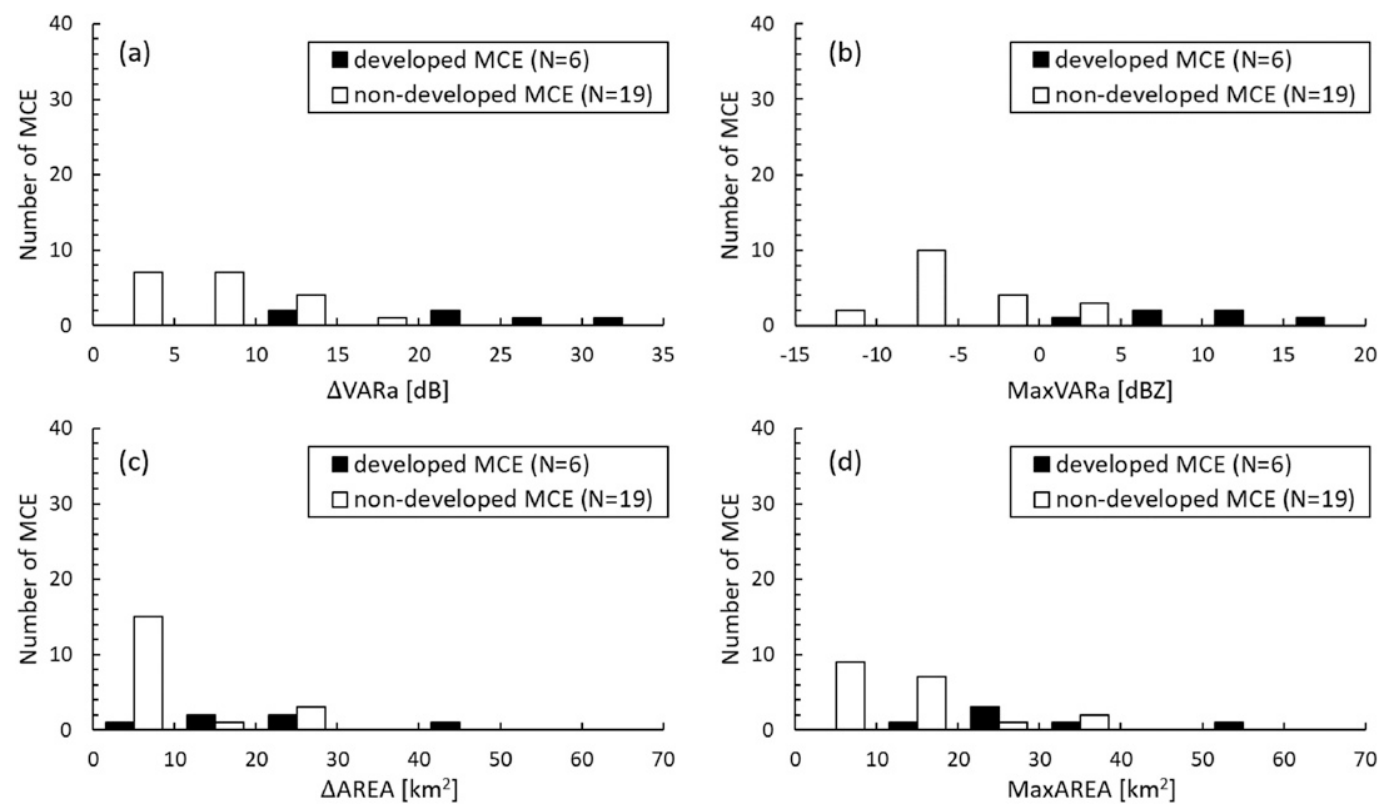

FIG. 7. Histograms of MCEs for (a) $\triangle$ VARa, (b) MaxVARa, (c) $\triangle$ AREA, and (d) MaxAREA for developed MCEs and non-developed MCEs for $\Delta t=15 \mathrm{~min} ; N$ represents the number of corresponding MCEs. 

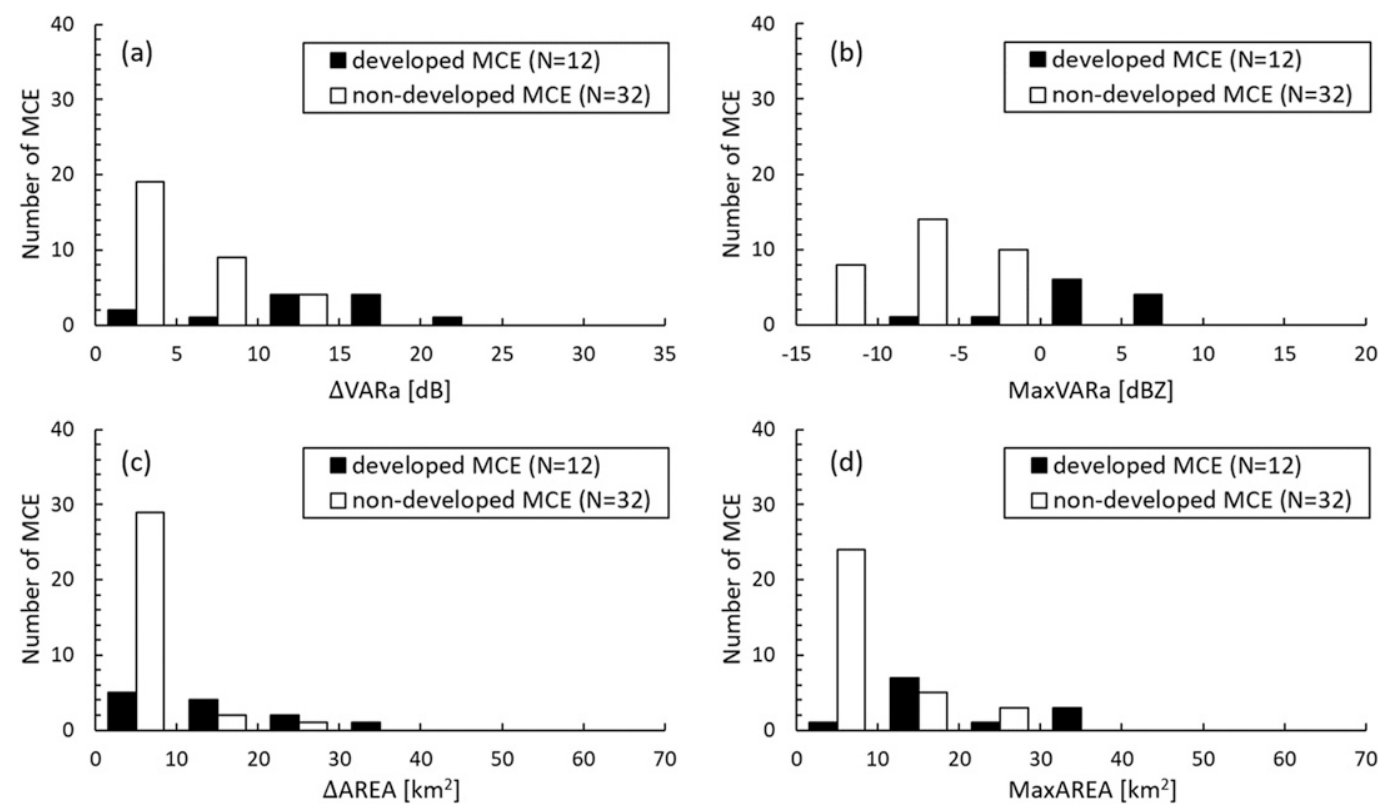

FIG. 8. As in Fig. 7, but for $\Delta t=9 \mathrm{~min}$.

Therefore, there is no significant difference at the initial stage of MCEs. However, the MaxVARa before the dissipation of MCEs was $-3.7 \mathrm{~dB} Z$ on average, which is much smaller than that of the developed MCEs $(12.9 \mathrm{dBZ}$ before the detection of MPEs). Similarly, the MaxAREA was $8.5 \mathrm{~km}^{2}$ on average for non-developed MCEs, which is smaller than that of the developed MCEs $\left(33.6 \mathrm{~km}^{2}\right)$.

Here, we define elapsed time $\Delta t$ as the time after the first detection of an MCE. Figure 7 shows histograms of $\Delta$ VARa, MaxVARa, $\Delta$ AREA, and MaxAREA for $\Delta t=15 \mathrm{~min}$. There
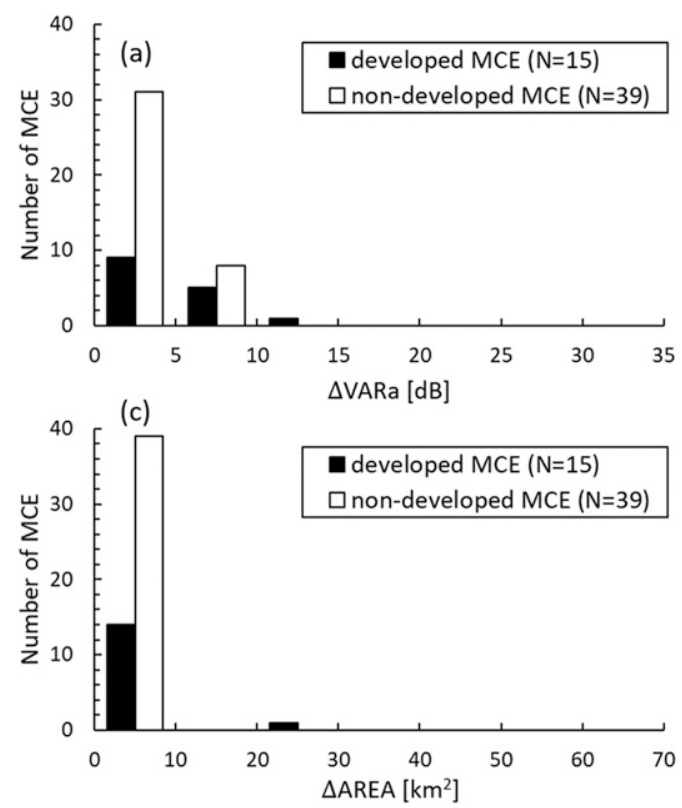

are differences between the developed and non-developed MCEs in terms of these variables. The MaxVARa values show a clear difference; they are always greater than $0 \mathrm{~dB} Z$ for developed MCEs and always smaller than $5 \mathrm{dBZ}$ for nondeveloped MCEs. The mean values of the MaxVARa were 13.4 and $-3.3 \mathrm{~dB} Z$ for the developed and non-developed MCEs, respectively. Differences are also clear for $\Delta t=9 \mathrm{~min}$ (Fig. 8), but not clear for $\Delta t=3 \mathrm{~min}$ (Fig. 9).

Table 5 shows the results of the Lepage test for $\Delta t=15,12,9$, 6 , and $3 \mathrm{~min}$ to examine whether the differences between the
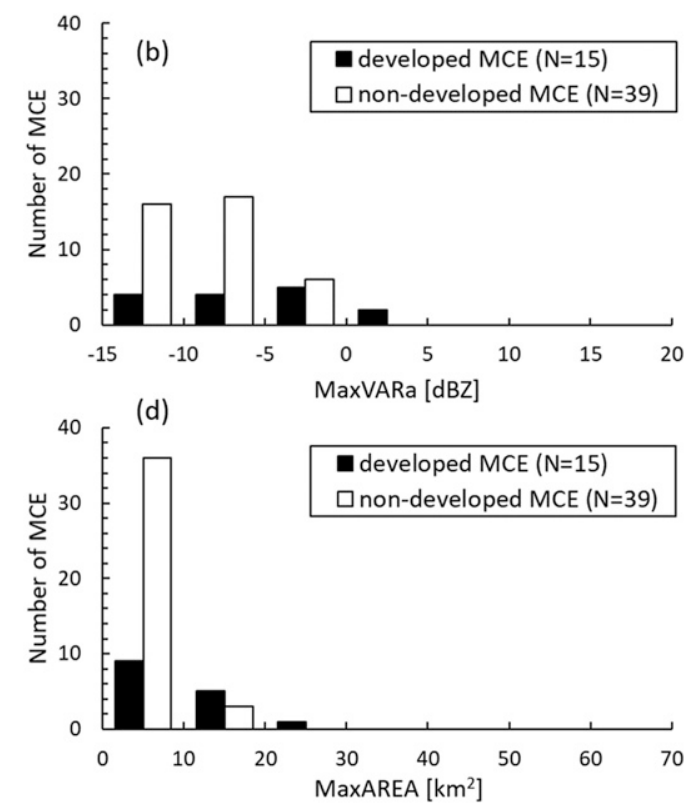

FIG. 9. As in Fig. 7, but for $\Delta t=3 \mathrm{~min}$. 
TABLE 5. Results of the Lepage test. The term $\Delta t$ indicates the elapsed time since the first detection of MCEs. When a value exceeds 9.21 , the difference is significant at the $99 \%$ confidence level.

\begin{tabular}{lrrrrr}
\hline \hline & \multicolumn{5}{c}{$\Delta t$} \\
\cline { 2 - 6 } Indicator & $3 \mathrm{~min}$ & $6 \mathrm{~min}$ & $9 \mathrm{~min}$ & $12 \mathrm{~min}$ & $15 \mathrm{~min}$ \\
\hline MaxVARa & 9.62 & 18.77 & 26.20 & 22.42 & 18.25 \\
$\Delta$ VARa & 5.78 & 15.44 & 18.97 & 16.13 & 14.36 \\
MaxAREA & 16.77 & 18.00 & 17.16 & 13.47 & 7.01 \\
$\Delta$ AREA & 17.27 & 17.27 & 17.82 & 15.12 & 7.98 \\
\hline
\end{tabular}

developed and non-developed MCEs were statistically significant. Except for some variables for $\Delta t=3$ and $15 \mathrm{~min}$, the differences were significant at the $99 \%$ confidence level. Among them, the highest value is for the MaxVARa for $\Delta t=$ $9 \mathrm{~min}$. Table 6 shows the threat score (TS) for the prediction of MPEs using each indicator, where the thresholds for predicting developed and non-developed MCEs for each indicator were chosen to maximize the TSs. MCEs whose $t_{1}$ was less than $\Delta t$ were excluded from the calculation of the TSs. The TSs are relatively high when the MaxVARa values were used as an indicator $(57.1 \%, 83.3 \%, 90 \%$, and $85.7 \%$ for $\Delta t=6,9,12$, and $15 \mathrm{~min}$, respectively). The TS is the highest for $\triangle \mathrm{AREA}$ $(58.8 \%)$ when $\Delta \mathrm{t}=3 \mathrm{~min}$. The mean lead times to the first detection of MPEs are 13.7, 10.7, 7.7, 4.7, and $1.7 \mathrm{~min}$ for $\Delta \mathrm{t}=$ $3,6,9,12$, and $15 \mathrm{~min}$, respectively. There is a trade-off between TSs and the lead time, which makes it difficult to declare the best indicator. Nevertheless the MaxVARa produces a TS of greater than $80 \%$ and thus provides reliable predictions. Therefore, the MaxVARa for $\Delta t=9 \mathrm{~min}$ (threshold: $0 \mathrm{dBZ}$ ) would be the best indicator for practical forecasting.

\section{Discussion}

In the previous section, we examined several variables that characterize the developed and non-developed MCEs. Among them, the MaxVARa for $\Delta t=9 \mathrm{~min}$ was found to be the best indicator that clearly distinguishes the developed and nondeveloped MCEs. In this section, we discuss a practical application of this indicator for predicting MCE development.

Here, we suppose that MCEs are detected based on the VAR field obtained from Ka-band radars at $t=t_{0}-\Delta t$ (Fig. 10). The VARa values of the MCEs are calculated from this time. After a time period $\Delta t$, forecasting starts only for MCEs whose MaxVARa value exceeds a certain threshold at time $t=t_{0}$. The MVs are calculated using the movements of MCEs for $t=t_{0}-\Delta t$ and $t_{0}$, and the locations of the MCEs are extrapolated to $T$ minutes ahead along the MV. Finally, the potential regions of heavy rainfall caused by MPEs are forecast along the movement area of the MCEs.

This algorithm aims to detect developing cumulonimbus clouds as early as possible and forecast their rainfall area. The time difference between the first detection of MCEs and MPEs is about $17 \mathrm{~min}$, and that between the first detection of MCEs and the peak time of MPEs is about $33 \mathrm{~min}$. Therefore, if $\Delta t=$ $9 \mathrm{~min}$ is used, the lead times for the detection of MPEs and their peak time will be 8 and $24 \mathrm{~min}$, respectively. The algorithm is also
TABLE 6. Maximum threat scores obtained using various indicators.

\begin{tabular}{lccccc}
\hline \hline & \multicolumn{5}{c}{$\Delta t$} \\
\cline { 2 - 6 } Indicator & $3 \mathrm{~min}$ & $6 \mathrm{~min}$ & $9 \mathrm{~min}$ & $12 \mathrm{~min}$ & $15 \mathrm{~min}$ \\
\hline MaxVARa & $40.9 \%$ & $57.1 \%$ & $83.3 \%$ & $90.0 \%$ & $85.7 \%$ \\
$\Delta$ VARa & $37.8 \%$ & $52.2 \%$ & $66.7 \%$ & $70.0 \%$ & $66.7 \%$ \\
MaxAREA & $52.6 \%$ & $55.0 \%$ & $64.7 \%$ & $71.4 \%$ & $55.6 \%$ \\
$\Delta$ AREA & $58.8 \%$ & $56.3 \%$ & $62.5 \%$ & $76.9 \%$ & $60.0 \%$ \\
\hline
\end{tabular}

feasible to $\mathrm{C}$ - or S-band radars instead of X-band radars. In such cases, the lead time may vary depending on radar sensitivity.

Next, we discuss the restrictions of the forecast using this indicator. First, this indicator is only applicable to convective echoes formed near Ka-band radar sites because the minimum detectable reflectivity decreases with the distance from radar sites due to attenuation. Because the observation area of Ka-band radars is narrow compared to that of centimeterwavelength radars, a network of many Ka-band radars is required. A wide observation area also makes it possible to apply this algorithm to fast-moving echoes. Second, the target of this algorithm is limited to isolated cumulonimbus clouds. For convective echoes accompanied by large precipitation systems such as squall lines, typhoon rainbands, or cold fronts, strong rain attenuation would affect the VAR value. In such cases, accurate observation of the VAR for weak echoes would be difficult.

In the present study, cumulonimbus clouds initiated by updrafts associated with the local convergence of sea breezes were considered. The investigation of other types of convective clouds that develop under different conditions, such as orographically induced convection, should also be undertaken. Unlike the case for the convergence of sea breezes, the updraft would be maintained for a relatively long time in mountainous areas, which may affect the VAR time variation. In future studies, we plan to evaluate the algorithm for more cases while taking into account the limitations mentioned above.

\section{Conclusions}

To detect cumulonimbus clouds in their early development stages and forecast their development, local heavy rainfall was observed by multiple Ka-band radars and operational X-band radars. The VAR was used to analyze the development of convective echoes. MCEs and MPEs were defined based on the VAR derived from Ka-band and X-band radars, respectively, and statistical analyses of the echoes and tracking information were performed. The results are summarized as follows:

1) The first detection time of MCEs was 17 min earlier than that of MPEs and 33 min earlier than the peak time of the VARa of MPEs on average.

2) There were statistically significant differences between developed and non-developed MCEs in terms of the MaxVARa, MaxAREA, $\triangle$ VARa, and $\triangle \mathrm{AREA}$ for 612 min after their first detection. Among these indicators, the MaxVARa showed the most statistically significant differences. 


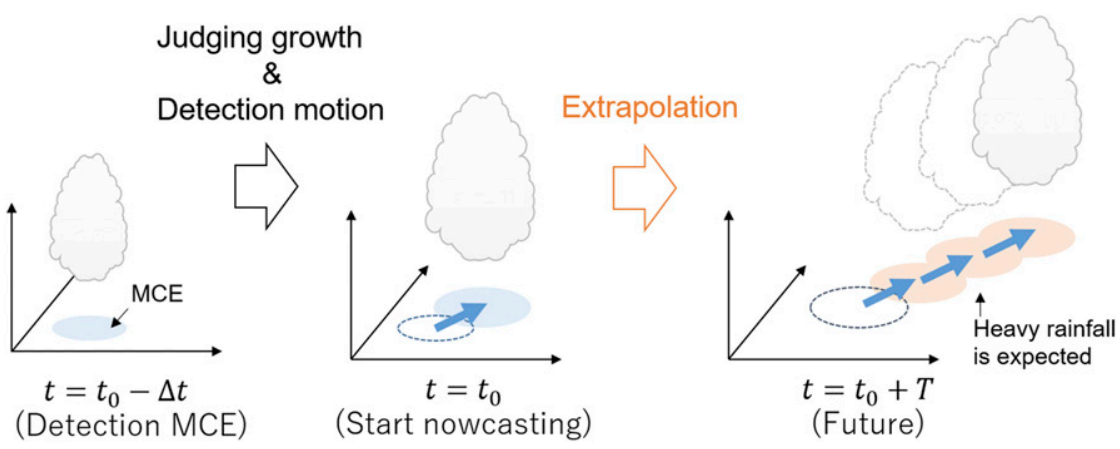

FIG. 10. Conceptual illustration of heavy rainfall forecast using the indicator developed in this study.

A nowcast algorithm for predicting MCE development was proposed using the MaxVARa as an indicator. This method is expected to forecast local heavy rainfall earlier than conventional X-band radars, although there are some restrictions on its use.

Acknowledgments. The Ministry of Land, Infrastructure, Transport, and Tourism XRAIN data were collected and provided under the Data Integration and Analysis System (DIAS) developed and operated by the Ministry of Education, Culture, Sports, Science, and Technology. The AITCC used in this study was provided by Dr. Shingo Shimizu of the National Research Institute for Earth Science and Disaster Resilience. The manuscript was greatly improved due to constructive comments from three anonymous reviewers. The authors would like to express their thanks to them.

\section{REFERENCES}

Borque, P., P. Kollias, and S. Giangrande, 2014: First observations of tracking clouds using scanning ARM cloud radars. J. Appl. Meteor. Climatol., 53, 2732-2746, https://doi.org/ 10.1175/JAMC-D-13-0182.1.

Chandrasekar, V., H. Fukatsu, and K. Mubarak, 2003: Global mapping of attenuation at $\mathrm{Ku}$ - and Ka-band. IEEE Trans. Geosci. Remote Sens., 41, 2166-2176, https://doi.org/10.1109/ TGRS.2003.815973.

Fujibe, F., K. Sakagami, K. Chubachi, and K. Yamashita, 2002: Surface wind patterns preceding short-time heavy rainfall in Tokyo in the afternoon of midsummer days (in Japanese with English abstract). Tenki, 49, 31-41.

Hamazu, K., H. Hashiguchi, T. Wakayama, T. Matsuda, R. J. Doviak, and S. Fukao, 2003: A 35-GHz scanning Doppler radar for fog observations. J. Atmos. Oceanic Technol., 20, 972-986, https://doi.org/10.1175/1520-0426(2003)20<972: AGSDRF $>2.0 . \mathrm{CO} ; 2$.

Hirano, K., and M. Maki, 2010: Method of VIL calculation for $\mathrm{X}$-band polarimetric radar and potential of VIL for nowcasting of localized severe rainfall-Case study of the Zoshigaya downpour, 5 August 2008. SOLA, 6, 89-92.

— and -2018 : Imminent nowcasting for severe rainfall using vertically integrated liquid water content derived from X-band polarimetric radar. J. Meteor. Soc. Japan, 96A, 201-220, https://doi.org/10.2151/jmsj.2018-028.

Ishihara, M., 2012: Radar echo population of thunderstorms generated on the 2008 Zoshigaya-rainstorm day and nowcasting of thunderstorm-induced local heavy rainfalls. Part I: Threedimensional radar echo population of the thunderstorms (in Japanese with English abstract). Tenki, 59, 27-39.

Khain, A., M. Pinsky, L. Magaritz, O. Krasnov, and H. W. J. Russchenberg, 2008: Combined observational and model investigations of the $Z$-LWC relationship in stratocumulus clouds. J. Appl. Meteor. Climatol., 47, 591-606, https://doi.org/ 10.1175/2007JAMC1701.1.

Kim, D.-S., M. Maki, S. Shimizu, and D.-I. Lee, 2012: X-band dualpolarization radar observations of precipitation core development and structure in a multicellular storm over Zoshigaya, Japan, on August 5, 2008. J. Meteor. Soc. Japan, 90, 701-719, https://doi.org/10.2151/jmsj.2012-509.

Kollias, P., N. Bharadwaj, K. Widener, I. Jo, and K. Johnson, 2014: Scanning ARM cloud radars. Part I: Operational sampling strategies. J. Atmos. Oceanic Technol., 31, 569-582, https:// doi.org/10.1175/JTECH-D-13-00044.1.

Maesaka, T., 2018: Cloud radars. Remote Sensing of Clouds and Precipitation, C. Andronache, Ed., Springer-Verlag, 137-152.

— M. Maki, K. Iwanami, S. Tsuchiya, K. Kieda, and A. Hoshi, 2011: Operational rainfall estimation by X-band MP radar network in MLIT, Japan. 35th Conf. on Radar Meteorology, Pittsburgh, PA, Amer. Meteor. Soc., P11.142, https://ams. confex.com/ams/35Radar/webprogram/Paper191685.html.

— K. Iwanami, S. Suzuki, Y. Shusse, and N. Sakurai, 2015: Cloud radar network in Tokyo metropolitan area for early detection of cumulonimbus generation. 37th Conf. on Radar Meteorology, Norman, OK, Amer. Meteor. Soc., 174, https://ams.confex.com/ ams/37RADAR/webprogram/Paper275910.html.

Matrosov, S. Y., 2005: Attenuation-based estimates of rainfall rates aloft with vertically pointing Ka-band radars. J. Atmos. Oceanic. Technol., 22, 43-54, https://doi.org/10.1175/JTECH1677.1.

Misumi, R., N. Sakurai, T. Maesaka, S. Suzuki, S. Shimizu, and K. Iwanami, 2018: Transition process from non-precipitating cumuli to precipitating convective clouds over mountains: Obsevation by Ka-band Doppler radar and stereo photogrammetry. J. Meteor. Soc. Japan, 96A, 51-66, https://doi.org/ 10.2151/jmsj.2017-021.

Nakakita, E., R. Nishiwaki, H. Yamabe, and K. Yamaguchi, 2013: Research on the prognostic risk of baby cell for guerillaheavy rainfall considering by vorticity with Doppler velocity (in Japanese with English abstract). J. Japan Ser. Civil Eng., 69B1, I_325-I_330, https://doi.org/10.2208/ jscejhe.69.1_325.

_ H. Sato, and K. Yamaguchi, 2016: Fundamental analysis of vortex tubes inside the baby cells of guerilla-heavy rainfall 
(in Japanese with English abstract). J. Japan Ser. Civil Eng., 69B1, I_199-I_204, https://doi.org/10.2208/jscejhe.72.I_199.

, T. Niibo, H. Sato, K. Yamaguchi, T. Ohigashi, T. Shinoda, and K. Tsuboki, 2017: Preliminary analysis of cumulonimbus cloud structure using multi parameter information of Ka-band polarimetric Dopper radar (in Japanese with English abstract). DPRI Annuals, 60B, 559-575.

Nishikawa, M., and Coauthors, 2016: Radar attenuation and reflectivity measurements of snow with dual Ka-band radar. IEEE Trans. Geosci. Remote Sens., 54, 714-722, https:// doi.org/10.1109/TGRS.2015.2464099.

Nishiwaki, N., and Coauthors, 2013: Behavior and structure of convective clouds developing around a mountainous area observed by stereo photogrammetry and Ka-band and X-band radars: Case study of Norther Kanto, Japan. J. Meteor. Soc. Japan, 91, 609-626, https://doi.org/10.2151/jmsj.2013-504.

Oh, S.-B., Y. H. Lee, J.-H. Jeong, Y.-H. Kim, and S. Joo, 2018: Estimation of the liquid water content and $Z$-LWC relationship using Ka-band cloud radar and a microwave radiometer. Meteor. Appl., 25, 423-434, https://doi.org/10.1002/met.1710.

Otsuka, S., and Coauthors, 2016: Precipitation nowcasting with threedimensional space-time extrapolation of dense and frequent phased-array weather radar observations. Wea. Forecasting, 31, 329-340, https://doi.org/10.1175/WAF-D-15-0063.1.

Saito, K., M. Kunii, and K. Araki, 2018: Cloud resolving simulation of a local heavy rainfall event on 26 August 2011 observed in TOMACS. J. Meteor. Soc. Japan, 96A, 175-199, https:// doi.org/10.2151/jmsj.2018-027.

Sakurai, N., K. Iwanami, T. Maesaka, S. Suzuki, S. Shimizu, R. Misumi, D.-S. Kim, and M. Maki, 2012: Case study of misoscale convective echo behavior associated with cumulonimbus development observed by Ka-band Doppler radar in the Kanto Region, Japan. SOLA, 8, 107-110.
Shimizu, S., and H. Uyeda, 2012: Algorithm for the identification and tracking of convective cells based on constant and adaptive threshold methods using a new cell-merging and -splitting scheme. J. Meteor. Soc. Japan, 90, 869-889, https://doi.org/ 10.2151/jmsj.2012-602.

Takahashi, N., and Coauthors, 2019: Development of multiparameter phased array radar (MP-PAWR) and early detection of torrential rainfall and tornado risk. J. Disaster Res., 14, 235-247, https://doi.org/10.20965/jdr.2019.p0235.

Uematsu, A., H. Hashiguchi, M. Teshiba, H. Tanaka, K. Hirashima, and S. Fukao, 2005: Moving cellular structure of fog echoes obtained with a millimeter-wave scanning Doppler radar at Kushiro, Japan. J. Appl. Meteor., 44, 1260-1273, https://doi.org/10.1175/ JAM2274.1.

Ushio, T., T. Wu, and S. Yoshida, 2015: Review of recent progress in lightning and thunderstorm detection techniques in Asia. Atmos. Res., 154, 89-102, https://doi.org/ 10.1016/j.atmosres.2014.10.001.

Yoshida, S., R. Misumi, S. Shimizu, T. Maesaka, K. Iwanami, and M. Maki, 2012: Validation of short-term forecasting of meso$\gamma$-scale convective systems based on a cell-tracking system. SOLA, 8, 141-144.

—, T. Ushio, S. Yoshida, S. Shimamura, K. Maruo, and N. Takada, 2013: The structure of convective systems observed by phased array radar in the Kinki region, Japan. 36th Conf. on Radar Meteorology, Breckenridge, CO, Amer. Meteor. Soc., 139, https://ams.confex.com/ams/36Radar/ webprogram/Paper228390.html.

Yoshikawa, E., T. Ushio, Z. Kawasaki, S. Yoshida, T. Morimoto, F. Mizutani, and M. Wada, 2013: MMSE beam forming on fast-scanning phased array weather radar. IEEE Trans. Geosci. Remote Sens., 51, 3077-3088, https://doi.org/10.1109/ TGRS.2012.2211607. 